\title{
Research on the Impact of Mobile Phone Clients for Travel Services on College Students' Travel Behavior
}

\author{
Shuang Wei, a ${ }^{1,}$ Qi Wei ${ }^{2, b}$ \\ ${ }^{1}$ Digital Culture and Media Research Center, University of Electronic Science and Technology of \\ China \\ ${ }^{2}$ Changge first high school of China \\ a361269693@qq.com, b2843910180@qq.com
}

Keywords: Handheld traveling, Share a bike, Travel Behavior

\begin{abstract}
For university students living in the 21st century, "handheld traveling" is no longer a distant dream. Since the beginning of 2012, the mobile media client with the mobile phone as the main platform has become the new favorite, and the emergence of the mobile clients of traveling service like the bicycle sharing has met the demand for timely information and has satisfied people's travel needs.
\end{abstract}

\section{Question proposing}

For university students living in the 21st century, "handheld traveling" is no longer a distant dream. Since the beginning of 2012, the mobile media client with the mobile phone as the main platform has become the new favorite, and the emergence of the mobile clients of traveling service like the bicycle sharing has met the demand for timely information and has satisfied people's travel needs.

At present, the recurrence of bicycle sharing has set off a wave of research related to the industry, many scholars began to get involved in mobile client research. At present, there are mainly two kinds of researches on travel behavior of smart phone client in our country. The first category mainly focuses on a specific type of mobile service client, and analyzes its role as a tool in people's travel behavior. The second type, though it involves people's travel behavior, only researches people's travel behavior from the macroscopic view of the Internet era, and does not associate the travel behavior with the mobile phone clients for travel services. To sum up, it can be seen that there is very little empirical research on the impact of domestic mobile phone service providers on mobile behavior of university students.

In this study, taking the online questionnaire as the main research approach, this paper investigates the use of mobile service clients in Henan University of Science and Technology, Luoyang Normal University and Luoyang Institute of Science and Technology by means of sample survey. A total of 325 data samples were collected. By analyzing the ways, processes and results of the influence of travel service mobile client on travel behavior of college students in Luoyang, this paper attempts to explore the influence of mobile client on travel dynamics of college students in real space.

\section{Research hypothesis}

Based on the quantitative analysis and content analysis of 325 survey samples, the author puts forward the following hypothesis: The travel behavior of university students using mobile service client is an acculturation process from cognitive transformation to behavior change.

This study will describe the data based on the sample survey and verify whether the hypothesis is validated by the bivariate cross-tabulation of and analysis of variance. 


\section{Impact of Travel Service APP on College Students' Travel Behavior}

\subsection{Impact of attitude}

According to social psychology defined by Friedman: Attitude is the evaluative and more stable intrinsic, psychological tendency of individual when react to a particular subject in a certain way. Attitude, as a determinant of behavior, has an important impact on the audience's actions and plays an important role. Therefore, when studying the impact of mobile phone clients for travel servicess on the travel behavior of college students, the attitude change is an important evaluation factor.

Through the investigation, it is found that 93.54\% college students' attitudes do change after making contact with mobile phone clients for travel servicess, they are willing to use the mobile clients of travel services. The assumption can be verified that the students of these three universities using mobile clients of travel services, is an acculturation process from cognitive transformation to behavior change, this change in attitude performs in behavior to some extent, prompting the subtle changes in university students' travel behavior in the use of mobile clients of travel services.

\subsection{Behavioral impact}

\subsubsection{Change college students' travel habits}

According to the survey, there are 93 people think that the using of mobile phone clients for travel services has changed the travel habits, accounting for $28.62 \%$ of the total.

The survey data show that the development of mobile phone clients for travel services has changed the students' traditional travel habits and broke the habit of college students in the traditional travel activities that need to solve various travel problems on the spot. Taking the taxi APP as an example, compared to the traditional travel habits, university students need to hail a taxi on the street before the emergence of taxi APP, and now through the use of mobile services such as mobile clients Didi Taxi, no longer to aimlessly looking for a taxi or aimlessly waiting, just to enter the time, location and destination, the system will automatically search a nearby taxi before departure, to achieve the purpose of taking a taxi.

\subsubsection{Change college students' travel status.}

According to the survey data about the impact of using the mobile service clients for mobile services, 129 people think that using the mobile service client has changed their travel habits, accounting for $39.69 \%$ of the total.

Travel groups on the traditional mode often stay in a passive position, they can not predict the traffic information and only to choose passively. The emergence of all kinds of mobile phone clients for travel servicess makes the travel service information transparent and open in time so that college students can taking the initiative by checking online at the travel platform built by mobile phone clients for travel services.

\subsubsection{Change college students' travel transaction way.}

Survey data show that in the "mobile clients for travel services to make my travel transaction way changes to online payment-based", 175 people think that the use of mobile phone clients for travel services changed their travel transaction way, accounting for $53.85 \%$ of the total. And 126 people think this is a normal state, accounting for $38.77 \%$ of the total.

From this we can conclude that after the emergence of mobile phone clients for travel services, college students accustomed to using "online payment" as the main means of payment for travel transactions. At the same time, mobile phone clients for travel services are consumer softwares, according to the survey results, a large part of people are willing to use online banking payment. The emergence of mobile phone clients for travel services makes the travel payment diversification of college students. University students can choose online payment on the basis of cash payment, 
which brings great convenience to their travel activities.

\section{Conclusion}

The mobile client, which is represented by the travel service, has had a tremendous impact on college students' travel life, which makes college students bid farewell to the traditional ways of travel and innovate their travel thinking, has brought efficient and good service to the travel life of university students. But at the same time, we must also recognize that the mobile client represented by travel service, as a kind of auxiliary software, can only take a secondary position in the travel life of university students. It can not substitute for human thinking to face its drawbacks. Colleges and universities students should learn to distinguish reasonably and select seriously. For mobile phone clients for travel services, we should be materialistic and dialectical, divide it into two aspects, can not all believe nor be over-general, correctly understand the travel services on behalf of the mobile clients, correctly use them, the mobile phone clients represented by the travel services play an important role in improving the travel services .

\section{References}

[1] Guo Qingguang. Communication Studies [M]. Beijing: Renmin University of China Press, 1999.

[2] Hu Yuanyuan. Mobile phone taxi APP system analysis [J]. Brand .2015.

[3] Zhu Pengyuan.Application behavior and psychological analysis of college students' mobile app - Case of five universities in Northwest China[J] .Southeast Communications, 2015.

[4] Yang Wenhao, Zhang Xiaoling, Zong Shuyu.Application behavior patterns of college students [J]. Modern Marketing, 2015.

[5] Song Qiuyan. Analyze the impacts of intelligent mobile phone's APP on students [J]. Computer Knowledge and Technology, 2014.

[6] Zhang Min, Sun Yang.An empirical analysis of university students' mobile phone social APP usage behavior - A Case Study of Shanghai Polytechnic University [J].

[7] Zhou Chonghua, Gao Zuogang et al. Research on traffic information service system for public travel on smart phone application [J]. Transport and Transportation, 2012.

[8] Li Jianzhou, Zhang Yunlai, Li Huifan. Mobile Internet in tourism application [J]. Journal of Tourism, 2011.

[9] Zhao Lin. Talk about the content and function of the mass media [J] Journal of Liaocheng University.2011.

[10]Zhang Yifan. Empirical study of customer satisfaction about China's tourism application[D].Department of Theses, 2015, Hainan University. 